\title{
Experimental Investigation of the Near Wake of a Pick-up Truck
}

\author{
Abdullah M. Al-Garni and Luis P. Bernal \\ University of Michigan \\ Bahram Khalighi \\ General Motors Corporation
}

Copyright @ 2003 Society of Automotive Engineers, Inc.

\begin{abstract}
The results of an experimental investigation of the flow over a pickup truck are presented. The main objectives of the study are to gain a better understanding of the flow structure in near wake region, and to obtain a detailed quantitative data set for validation of numerical simulations of this flow. Experiments were conducted at moderate Reynolds numbers $\left(\sim 3 \times 10^{5}\right)$ in the open return tunnel at the University of Michigan. Measured quantities include: the mean pressure on the symmetry plane, unsteady pressure in the bed, and Particle Image Velocimetry (PIV) measurements of the flow in the near wake. The unsteady pressure results show that pressure fluctuations in the forward section of the bed are small and increase significantly at the edge of the tailgate. Pressure fluctuation spectra at the edge of the tailgate show a spectral peak at a Strouhal number of 0.07 and large energy content at very low frequency. The velocity field measurements in the symmetry plane show that shear layers form at the top of the cab and the underbody flow region. The cab shear layer evolves more slowly than the underbody flow shear layer and does not interact strongly with the tailgate for the present geometry. Behind the tailgate there is no recirculating flow region in the symmetry plane believed to be due to downwash from streamwise vorticity in the near wake. There are small recirculating regions on the sides of the tailgate symmetry plane extending approximately one tailgate height downstream.
\end{abstract}

\section{INTRODUCTION}

Pickup trucks are one of the more popular vehicle geometries in use today yet it has received very little attention in the car aerodynamics literature. The aerodynamics of pickup trucks is more complex than other open bed trucks because the short length of the bed can result in interaction of the bed walls and tailgate with the separated shear layer formed at the edge of the cab. The complexity of the flow makes drag prediction tools, including CFD based methods, unreliable. The main goal of the present research is to gain a better understanding of pickup truck aerodynamics using detailed flow field measurements that can also be used for validation of computational models.

The aerodynamics of road vehicles has frequently been studied in simplified geometries to separate the effect of various components on aerodynamic drag and on near wake flow dynamics. A review of early work in this area can be found in Hucho. ${ }^{1}$ Particularly relevant to the present work are the investigations by Balkanyi and coworkers $^{2-4}$ on the effects of drag reducing devices on the near wake flow. PIV measurements and unsteady pressure measurements show that the near wake turbulence structure is modified by the drag reducing devices. The turbulence intensity is reduced while the shape and downstream extent of the recirculating flow region is not strongly affected. In several configurations, a peak in the pressure fluctuation power spectra is found at a Strouhal number based on model width of 0.1 . This peak is not present in cases with larger drag reduction. These results are consistent with the results of full scale tests of a tractor trailer vehicle by Lanser et $a F^{5}$. Duell and George ${ }^{6}$ report unsteady flow effects in the near wake of a three-dimensional bluff body with a blunt base similar to the one used by Balkanyi and co-workers. They differentiate between unsteady effects in the separated shear layer at the edge of the body and the closed recirculating flow region. The initial development of the separated shear layer is dominated by vortex rollup and merging processes with a characteristic Strouhal number $\sim 1$. In contrast the wake pumping associated with unsteadiness of the recirculating flow region has a characteristic Strouhal number $\sim 0.07$. Recently Leitz et $\mathrm{al}^{7}$ have reported results of numerical simulations and experiments of the flow behind the tailgate of a pickup truck. An important difference between the pickup truck flow and the simplified geometries discussed earlier are the streamwise vortices that form in the near wake of the pickup truck.

In this paper we present results of an experimental program that aims at gaining a better understanding of the flow in the near wake of a pickup truck. We use the wind tunnel PIV system developed by Balkanyi et al ${ }^{2}$ to document the structure of the turbulent flow in the near 
wake. Among the data reported are measurements of mean and fluctuating pressures on the model surface, and mean and turbulent velocities in the near wake.

\section{FLOW FACILILITIES AND INSTRUMENTATION}

\section{WIND TUNNEL FACILITY}

The experiments were conducted in the 2'x2' Wind Tunnel at the Aerospace Engineering Department at the University of Michigan. This is an open-return suction wind tunnel equipped with glass side and bottom test section walls for optical access. The maximum speed of the tunnel is approximately $35 \mathrm{~m} / \mathrm{s}$ and the test section cross-section area is approximately $0.60 \times 0.60 \mathrm{~m}^{2}$. The test section has $0.14 \mathrm{~m}$ fillets at the bottom corners to suppress corner flows. For the present tests a 2- $m$ long ground board mounted $0.1 \mathrm{~m}$ below the top wall of the test section was used to simulate ground effects on the pickup truck flow. The ground board spans the cross section of the tunnel and has a rounded leading edge of elliptical cross section with $4: 1$ aspect ratio. Figure 1 shows a schematic diagram of the wind tunnel test section with the pickup truck model installed and the PIV setup for velocity measurements in the symmetry plane.

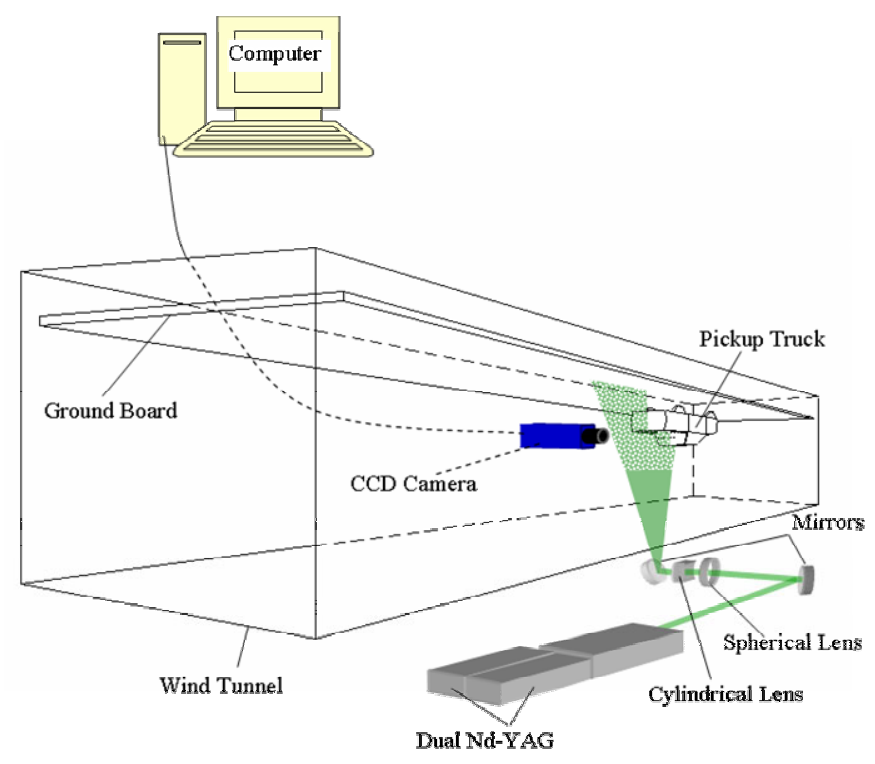

Figure 1. Schematic diagram of the wind tunnel setup.

\section{PICKUP TRUCK MODEL}

The pickup truck model is shown schematically in Figure 2. The main features are a relatively long cabin (the "Cab") and a short bed (the "Bed") compared to other truck geometries. For the tests, the model was mounted upside down on the bottom side of the ground board with attachment points at the wheels. Holes in the wheels provided access for pressure lines and/or electrical cables. The front bumper is located approximately $0.4 \mathrm{~m}$ from the leading edge of the ground board. As shown in Figure 2, the length of the model is $0.432 \mathrm{~m}$, the width is $0.152 \mathrm{~m}$, and the height is $0.148 \mathrm{~m}$ measured from the ground board. The maximum cross section area is $0.019 \mathrm{~m}^{2}$, which gives a blockage area ratio of $6 \%$. Although the blockage is small, it has a significant effect on the flow causing significant acceleration of the flow around the model and a reduced static pressure at the bottom of the test section under the model. To account for blockage effects, the static pressure on the fillets was measured in the tests and used to calculate the pressure coefficient as discussed below. Also shown in Figure 2 is the origin of the coordinate system used in this paper. The x-axis is in the flow direction with its origin at the front bumper. The $y$-axis is in the horizontal direction across the flow with its origin at the symmetry plane of the model. The z-axis is in the vertical direction with its origin at the bed floor.

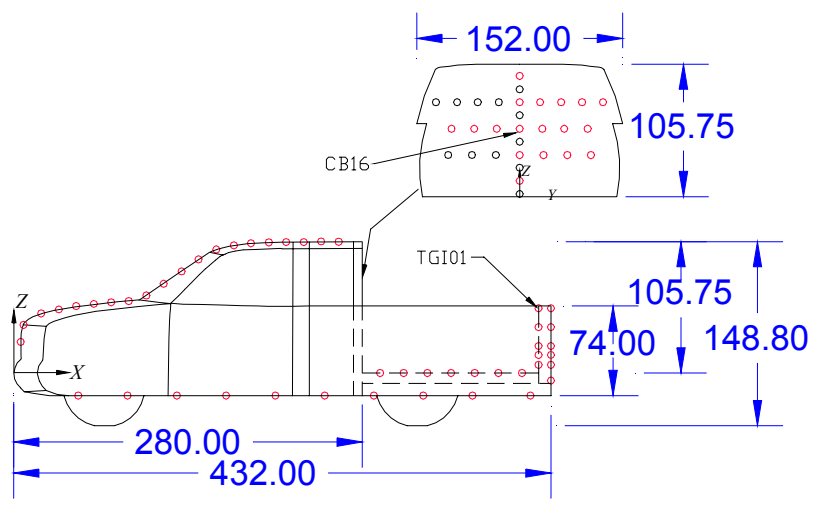

Figure 2. Side view drawing of the pickup truck model and rear view of the cab base showing in the insert.

The model was instrumented with various pressure taps located on the symmetry plane of the cab, bed, tailgate and underbody surface. Figure 2 shows the locations of pressure taps on the symmetry plane and cab base. Both the inside and outside surfaces of the tailgate were instrumented. Unsteady pressure measurements were conducted at several locations in the bed. Of these only the data obtained at pressure taps marked CB16 and TGI01 in Figure 2, at the center of the base and top of the tailgate, respectively, are reported here because they capture the main features of the flow.

\section{PRESSURE MEASUREMENTS}

The mean pressure was measured with a manometer rake. The pressure lines, 1- $\mathrm{mm}$ Teflon tubing, were installed inside the model and routed through access holes in the wheels and wind tunnel wall to minimize flow disturbances. The length of the pressure lines was approximately $1.2 \mathrm{~m}$. For the present measurements the reference pressure is the static pressure measured at the pressure port on the bottom fillet located approximately at the same downstream location as the cab base. The measurement uncertainty of the mean pressure coefficient was evaluated for each test and found to be less than $0.3 \%$ in all cases. 
Time-Resolved pressure measurements were conducted using a Validyne PD-305D pressure transducer. The range of the pressure transducer for the diaphragm used was 3.5 inches of water $(\sim 900 \mathrm{~Pa})$. The transducer was installed inside the cab wrapped in soft cloth to minimize vibrations. The pressure line used to connect the transducer to the pressure taps was as short as practical, about $0.15 \mathrm{~m}$. The reference pressure side of the transducer was connected to the same pressure tap on the bottom fillet used for the mean pressure measurements. The transducer's power and signal cables were routed through the access holes in the wheels and wind tunnel wall to minimize flow disturbances.

The analog output of the transducer was DC-shifted, amplified and filtered using a Tektronix AM-402 instrumentation amplifier and digitized using a National Instruments data acquisition board $\mathrm{PCl}-6023 \mathrm{E}$. The data were then deconditioned and converted to pressure using the calibration curve. After some preliminary tests, the output filter of the instrumentation amplifier was configured as a low-pass filter with a cut-off frequency of $100 \mathrm{~Hz}$. The sampling frequency was $250 \mathrm{~Hz}$ in all the tests. Moreover, the pressure transducer was calibrated repeatedly and shown to give reproducible results within the uncertainty of the measurements, which is approximately $2 \%$ of the transducer range $(\sim 18 \mathrm{~Pa})$. The amplifier gain determines the digitization resolution, which was found to be better than $0.039 \mathrm{~Pa}$ for the present tests.

\section{PARTICLE IMAGE VELOCIMETRY}

The velocity field on selected planes was measured using a two-frame digital PIV system. The flow was illuminated using two Nd-YAG lasers. The output beams were merged, shaped into a light sheet by a combination of spherical and cylindrical lenses, and directed into the test section by mirrors. The optical setup produced a laser sheet $0.5 \mathrm{~mm}$ thick by $400 \mathrm{~mm}$ wide. The lasers were synchronized to illuminate the flow twice with a short time delay between the two exposures. The time delay was chosen to produce a particle displacement of approximately 2 pixels. Actual values used were in the range 15 to $30 \mu \mathrm{s}$, depending on the field of view and flow speed.

The flow was seeded with small oil particles generated by a smoke generator located upstream of the settling chamber. The smoke was directed into a 'smoke box' designed to produce a uniform smoke stream. The cross-section area of the smoke stream in the test section was $20 \times 20 \mathrm{~cm}$.

PIV image acquisition varied slightly depending on the particular plane being studied. In all cases PIV images were recorded with a high-resolution dual-frame digital camera $(1280 \times 1024$ pixels $)$. In the symmetry plane, the field of view of PIV images of the flow outside the bed was $320 \times 260 \mathrm{~mm}$ resulting in a spatial resolution of 4 pixels $/ \mathrm{mm}$. Also in the symmetry plane, the field of view of PIV images of the flow in the bed was $127 \times 100$ $\mathrm{mm}$, which corresponds to a spatial resolution of 8 pixels $/ \mathrm{mm}$. For these measurements the bed walls were made of transparent acrylic plate to provide optical access inside the bed. For the horizontal plane PIV images the field of view was $310 \mathrm{~mm} \times 246 \mathrm{~mm}$, which corresponds to a spatial resolution of 4 pixels $/ \mathrm{mm}$. In all cases typical particle displacements were approximately 2 pixels. The images were collected at a rate of $1 \mathrm{~Hz}$ limited by the transfer time of the digital images to the data acquisition computer. A total of 360 PIV images were recorded at each plane for each Reynolds number tested.

The PIV images were processed using an image shifting algorithm consisting of two steps. In the first step, the images are processed using a standard cross correlation algorithm on un-shifted interrogation windows to determine the particle displacement at each grid point. The interrogation window size is large enough to accommodate the expected particle displacement. In the second step, cross correlation analysis between shifted interrogation windows is used. The window shift at each grid point is the particle displacement obtained in the first step. The main advantage of this technique is that the measurement resolution is decoupled from the particle displacement and consequently the noise level of the PIV measurement is improved. The interrogation window used in the second step determines the spatial resolution of the measurement. For the present measurements the interrogation window used was $64 \mathrm{x}$ 64 pixels and the grid spacing was 16 pixels, which correspond to a window size in the flow of $16 \times 16 \mathrm{~mm}$ and $4 \mathrm{~mm}$ grid spacing for the measurements outside the bed, and $8 \times 8 \mathrm{~mm}$ and $2 \mathrm{~mm}$ for the measurements inside the bed. The corresponding values for the horizontal plane are $16 \times 16 \mathrm{~mm}$ interrogation window size and $4 \mathrm{~mm}$ grid spacing.

The PIV data were processed to obtain mean and turbulence properties in the wake of the pickup truck. The grids used in the symmetry plane were $73 \times 43$ points outside the bed, and $59 \times 21$ points inside the bed. For the horizontal plane the grid used was $74 \times 52$ points. In the analysis of turbulent data, each PIV velocity field is treated as an independent realization of the flow since the time between samples (1s) is long compared to the turbulence time scales. Ensemble averages of 300 instantaneous fields are reported. The uncertainty of the mean velocities is estimated to be less than $2 \%$.

\section{RESULTS AND DISCUSSION}

\section{MEAN PRESSURE MEASUREMENTS}

The mean pressure coefficient measured along the symmetry plane of the model is shown in Figure 3 at Reynolds numbers $1.74 \times 10^{5}, 2.36 \times 10^{5}$ and $2.88 \times$ $10^{5}$, which correspond to wind tunnel speeds of 18,25 and $30 \mathrm{~m} / \mathrm{s}$, respectively. The mean pressure distribution on the engine hood and passenger cabin is marked 
"Cab." It shows the expected features. At the front bumper there is a stagnation point, $C_{p}=1$. The flow accelerates to a local maximum velocity around the front of the engine compartment where the local pressure coefficient is $\sim-0.4$. On the hood the flow speed decreases and the pressure increases to a local maximum of the pressure coefficient, $C_{p}=0.5$, at the lower corner of the windshield (point 9 in Figure 3). On the windshield the flow speed increases and the pressure coefficient decrease to a minimum value of -0.9 at the top of the windshield (point 13 in Figure 3). On the top of the cabin, the flow speed decreases and the pressure coefficient increases to -0.2. The pressure distribution on the bottom of the pickup truck is marked "Bottom" in Figure 3. The pressure coefficient varies slightly with local minima $\left(C_{p} \sim-0.2\right)$ at $\mathrm{x} \sim 100 \mathrm{~mm}$ and $x \sim 350 \mathrm{~mm}$, which correspond to the locations of the wheels. The local decrease of the pressure on the bottom surface at the location of the wheels is attributed to the local acceleration of the underbody flow due to the reduced flow cross section area at the wheels. The pressure coefficient in the pickup truck bed is marked "Bed" in Figure 3. The pressure coefficient is approximately -0.3 and increases to $\sim-0.2$ towards the tailgate. The pressure coefficient in the bed shows a weak but significant Reynolds number dependence. At the lowest Reynolds number tested the pressure coefficient is lower by $\sim 0.05$ compared to the results at higher Reynolds numbers.

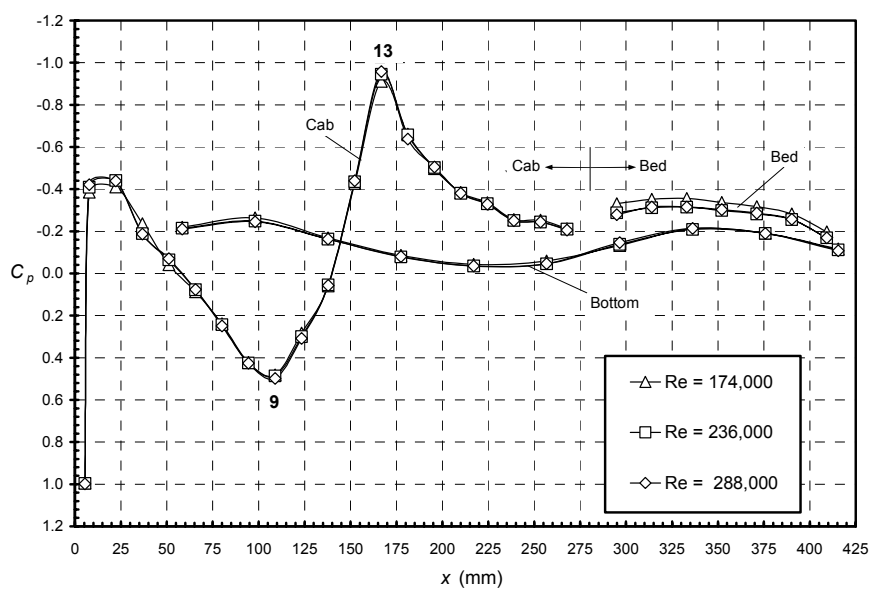

Figure 3. Mean pressure coefficient distribution measured on the symmetry plane of the pickup truck.

The pressure coefficients measured on the back surface of the cab are shown in Figure 4. At high Reynolds number the pressure coefficient has a minimum value $\left(C_{p} \sim-0.35\right)$ at approximately the center of the base $(z \sim 50 \mathrm{~mm})$. The pressure coefficient increases towards the top of the cab and towards the bed surface. There is a significant decrease of the pressure coefficient ( 0.05 ) at the lowest Reynolds number in the lower two thirds of the cab base $(0<z<70 \mathrm{~mm})$. This trend is reversed near the top of the cab base were the pressure coefficient increases to -0.14 at the lowest Reynolds number compared to $C_{p}$ values of -0.30 and -0.32 at the intermediate and high Reynolds numbers, respectively.

The pressure coefficient distribution on the symmetry plane of the tailgate is shown in Figure 5 . The results on the outside and inside surfaces of the tailgate are shown in the figure as marked. The pressure coefficient outside the bed shows good collapse of the data at the three Reynolds numbers tested. The minimum pressure coefficient of -0.17 is found at $z \sim 25 \mathrm{~mm}$ and increases slightly to -0.12 at the top and the bottom edges of the tailgate. In contrast the pressure coefficient distribution on the inside surface of the tailgate shows slightly lower values $(\sim-0.025)$ at the lower Reynolds number. In addition there is rapid decrease of the pressure coefficient at the edge of the tailgate, indicating a rapid acceleration of the flow in this region. Finally note that the mean pressure on the inside surface of the tailgate is lower than on the outside surface suggesting that the force acting on the tailgate is in the forward direction, reducing aerodynamic drag.

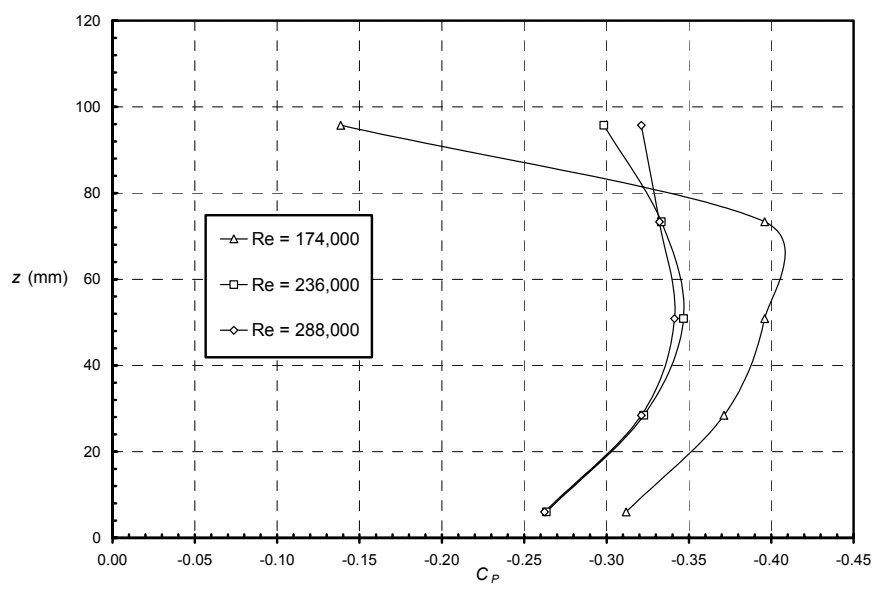

Figure 4. Pressure distributions measured on the symmetry plane of the back surface of the cabin.

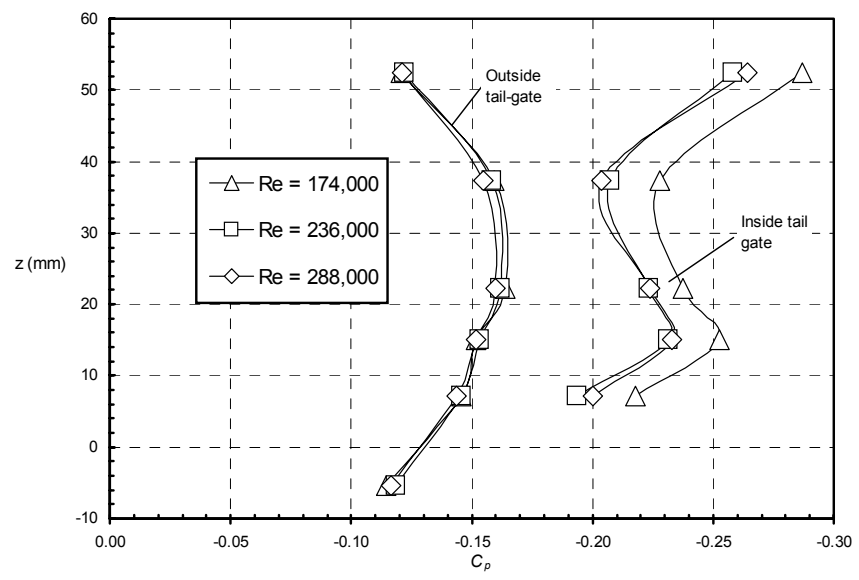

Figure 5. Pressure coefficient distribution measured on the symmetry plane of the inside and outside surfaces of the tailgate of the pickup truck. Note that the z-axis' origin is at the surface of the bed and there is a pressure tap on the outside surface located below the surface of the bed. 


\section{UNSTEADY PRESSURE MEASUREMENTS}

The unsteady pressure data were processed to determine the spectrum of the pressure coefficient fluctuations. The non-dimensional form of the pressure spectrum is defined as

$$
\Phi^{*}=\Phi_{\mathrm{pp}} \frac{\mathrm{U}}{\mathrm{q}^{2} \mathrm{D}},
$$

with

$$
\begin{aligned}
& \Phi_{p p}(f)=\int_{-\infty}^{\infty} R_{p p}(\tau) \exp (-i 2 \pi f \tau) d \tau \\
& R_{p p}(\tau)=\int_{-\infty}^{\infty} \Phi_{p p}(f) \exp (i 2 \pi f \tau) d f
\end{aligned}
$$

where $\Phi_{\mathrm{pp}}$ is the pressure spectra, $\mathrm{f}$ is the frequency in $H z, R_{p p}$ is the pressure fluctuation autocorrelation, $\tau$ is the autocorrelation time delay in seconds, $\mathrm{U}$ is the free stream speed and $D$ is the width of the model. The frequency is non-dimensionalized with the free stream speed, $U$, and the width of the model, $D$, which gives the Strouhal number, $f^{*}=f D / U$. For the unsteady pressure measurements, data records $400 \mathrm{~s}$ long $(100,000$ points $)$ were recorded at each test condition. The frequency resolution of the pressure fluctuation spectrum is $0.24 \mathrm{~Hz}$.

Table 1 lists the rms values of the pressure coefficient fluctuations at two locations inside the bed representative of the spectra in the forward side of the bed and the tailgate respectively. The mean pressure coefficients are in general good agreement with the results of the manometer measurements. In the cab base at CB16, the magnitude of the pressure fluctuations is very small, less than $0.5 \%$ of the dynamic pressure. In contrast, at the tailgate edge (port TGI01) the $r m s$ values of the pressure fluctuation are about $2 \%$ of the dynamic pressure, a factor five larger than at the base of the bed. The effect of Reynolds number on the

\begin{tabular}{|c|c|c|c|c|}
\hline Pressure Port & $U(\mathrm{~m} / \mathrm{s})$ & 18 & 25 & 30 \\
\hline riessure fort & $\operatorname{Re}$ & 174,000 & 236,000 & 288,000 \\
\hline CB16 & $\sqrt{\overline{c_{p}{ }^{\prime 2}}}$ & 0.0042 & 0.0039 & 0.0038 \\
\hline TGI01 & $\sqrt{\mathrm{C}_{\mathrm{p}}{ }^{\prime 2}}$ & 0.0184 & 0.0186 & 0.0193 \\
\hline
\end{tabular}
$r m s$ is small of the order of the measurement uncertainty.

Table 1. Root-Mean-Square $(r m s)$ values of the pressure coefficient fluctuation at pressure ports CB16 and TGI01.

The pressure coefficient spectra measured at the three Reynolds numbers used in this study are shown in Figure 6 for the two locations listed in Table 1. The nondimensional power spectra are plotted as a function of Strouhal number. The roll-off of the spectra at high Strouhal number is determined by the filter setting (100 $\mathrm{Hz}$ ), which is the same for all the tests, and therefore the non-dimensional values vary with flow speed. There is good collapse of the data at the different speeds indicating that the present non-dimensionalization captures the relevant flow dynamics. The spectra at the base of the cab (port CB16) shown in Figure 6(a) are typical of spectra measured in the forward part of the bed. Common features include: large spectral density at low frequency possibly due to unsteadiness of the recirculating flow in the wind tunnel lab; several peaks in the frequency range $f^{*} \sim 0.1-1$ associated with electrical noise in the system; and a number of broad peaks at $f^{*} \sim 0.1$ associated with the details of the pickup truck flow. As noted in Table 1 the pressure fluctuation amplitude is very low at this location and therefore the measured spectra are strongly influenced by system noise.

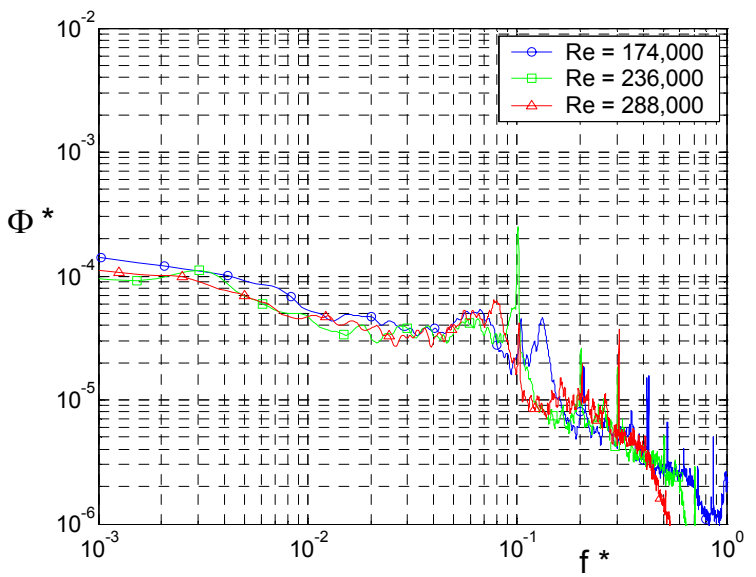

(a)

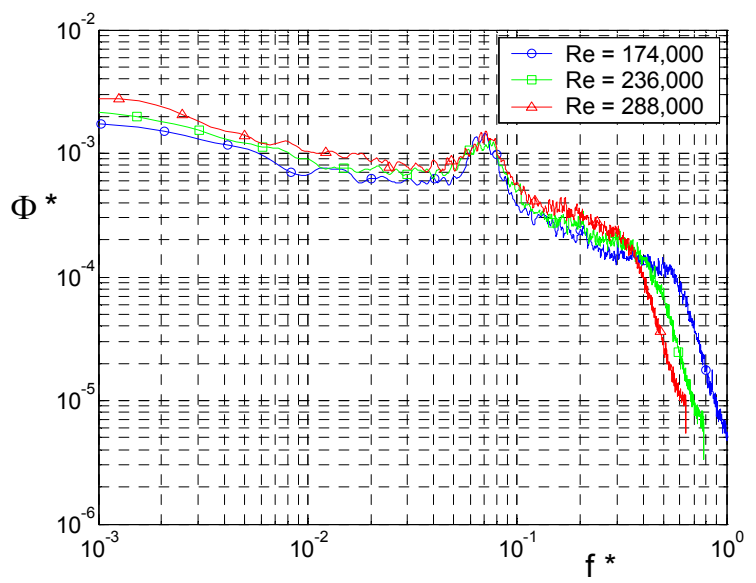

(b)

Figure 6. Spectra of the pressure coefficient fluctuation measured at pressure ports: (a) CB16 and (b) TGI01.

The pressure fluctuation spectra at the edge of the tailgate are shown in Figure 6(b). In this case the pressure fluctuation amplitude is five times larger than at the cab base. The main features of the spectra are a broad peak at low frequency and a Strouhal peak at $f^{*}=0.07$. This result is in agreement with the results obtained in blunt based models ${ }^{2-4,6}$ and full scale tests. 
An interesting common feature of all the spectral data measured in these tests is that the maximum spectral density occurs at very low frequencies. The magnitude of the spectral density at these low frequencies is several orders of magnitude larger than the spectral density of the total pressure fluctuations at the same frequency. Clearly, the pickup truck flow amplifies small amplitude fluctuations in the free stream. From a practical point of view, the sensitivity of the pickup truck flow to small free stream disturbances is important since it can lead to increased drag and directly impact vehicle dynamics.

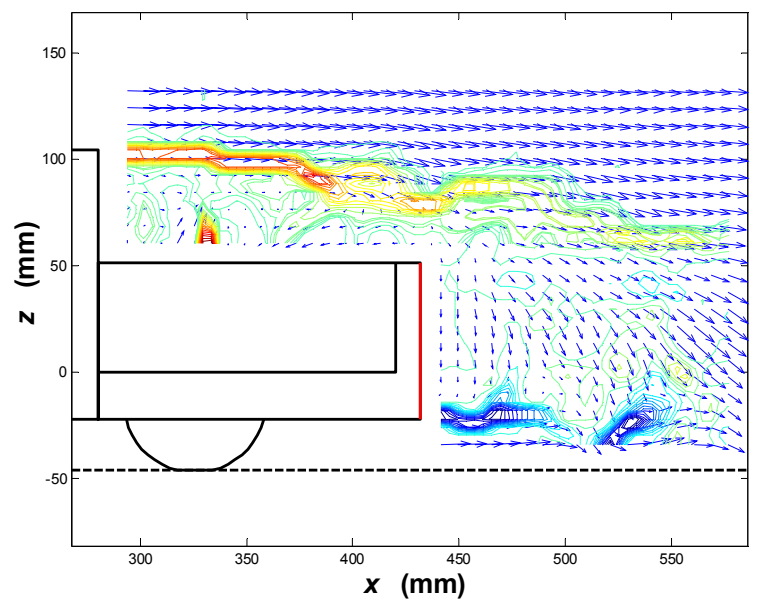

Figure 7. Instantaneous velocity and vorticity fields in the symmetry plane of the wake of a pickup truck at a free stream velocity $30 \mathrm{~m} / \mathrm{s}\left(\operatorname{Re}=2.88 \times 10^{5}\right)$.

\section{VELOCITY MEASUREMENTS}

PIV measurements of the flow field were obtained on several planes in the pickup truck wake. The tests were conducted at the same Reynolds numbers as the pressure measurements on the symmetry plane of the pickup truck (i.e. normal to the ground board). A typical instantaneous flow field in the symmetry plane is shown in Figure 7. The figure shows a combined velocity vector plot and normal vorticity contour plot of the flow. The main features of the flow are the cab shear layer originating at the edge of the cab, and the underbody shear layer that originates at the bottom edge of the tailgate. The spatial resolution of these measurements is not sufficient to resolve the structure of the vorticity field close to the separation point of these shear layers. However vortical structures spaced approximately 50 $\mathrm{mm}$ are observed in both shear layers farther downstream. The high vorticity region in the cab shear layer is well above the top of the tailgate, although there is significant upstream flow into the bed just upstream of the tailgate. A striking feature of the flow is the lack of recirculating flow region behind the tailgate.

Figures 8 shows a vector plot of the mean velocity field superposed on a contour line plot of the mean vorticity field in the symmetry plane. The regions of high vorticity in this figure are the locations of the cab and the underbody flow shear layers. Both shear layers extend to approximately the same streamwise location ( 550 $\mathrm{mm}$ ). Figure 9 shows the mean streamlines of the flow. The plot includes the mean streamlines inside the bed obtained in separate tests. The streamline pattern inside the bed matches well with the streamline pattern outside the bed. A recirculating flow region exists behind the cabin but there is no recirculation behind the tailgate. Instead the mean flow shows a very strong downwash at the symmetry plane. This is due to the presence of a strong streamwise vorticity behind the tailgate. ${ }^{7}$ These results show that the flow enters the bed at the tailgate and leaves near the cab base resulting in a recirculation region in the front part of the bed with its center approximately $40 \mathrm{~mm}$ behind the cab base.

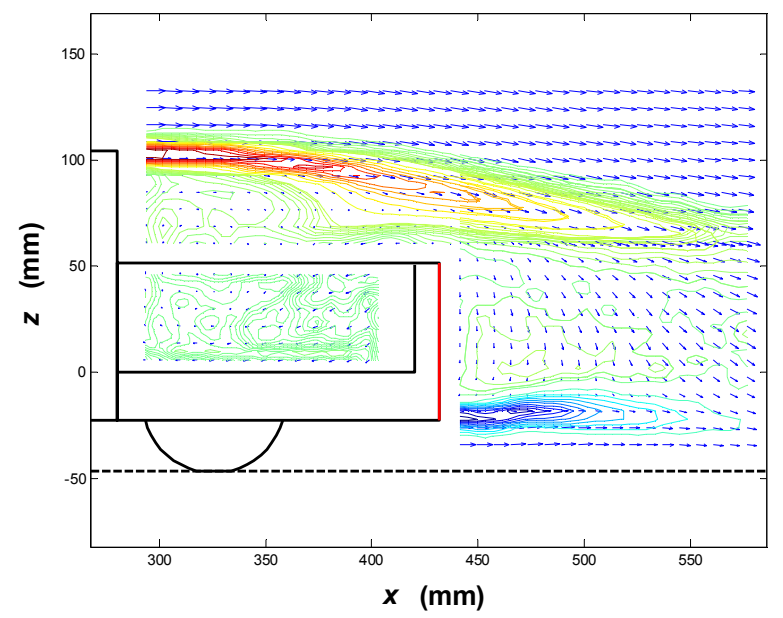

Figure 8. Mean velocity field and vorticity fields in the symmetry plane of the wake of a pickup truck. $\left(\operatorname{Re}=2.88 \times 10^{5}\right)$.

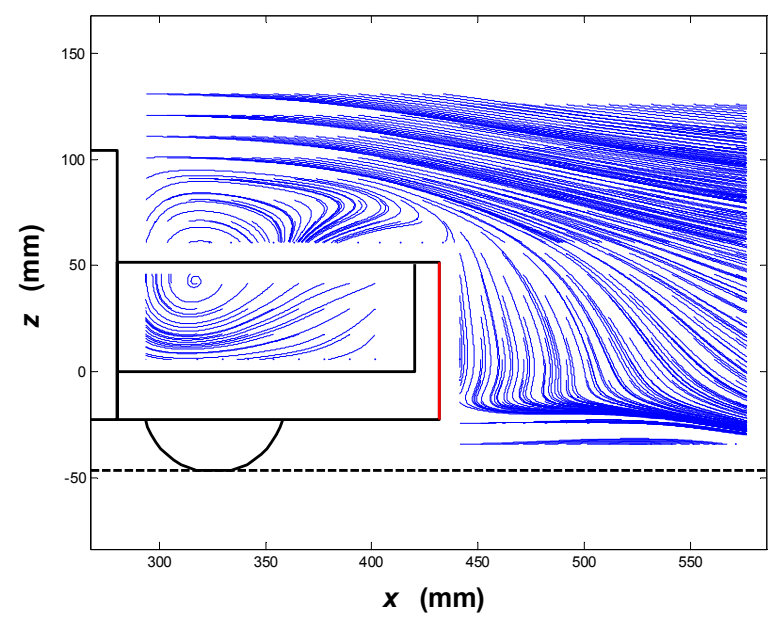

Figure 9. Streamlines of the mean velocity field at the symmetry plane $\left(\operatorname{Re}=2.88 \times 10^{5}\right)$.

Figure 10 shows a typical instantaneous velocity and vorticity field in the horizontal plane $z=15 \mathrm{~mm}$ behind the tailgate, which corresponds to approximately the mid point of the tailgate. As expected shear layers form at the edges of the tailgate. Near the separation point the spatial resolution of these measurements is not sufficient to resolve the initial vorticity development. Undulations with wavelength $\sim 50 \quad \mathrm{~mm}$ develop downstream 
suggesting the formation of vortical structures. A few high vorticity regions are observed in this region. However, the flow is highly three-dimensional as indicated by the outflow regions at $y \sim \pm 50 \mathrm{~mm}, \mathrm{x} \sim 525$ $\mathrm{mm}$ indicating strong normal flow into the plane of the measurements. Regions of reversed flow are located away from the symmetry plane near the tailgate just upstream of the outflow regions. At the symmetry plane the flow is in the downstream direction a very short distance from the tailgate. These flow features are consistent with the results in the symmetry plane.

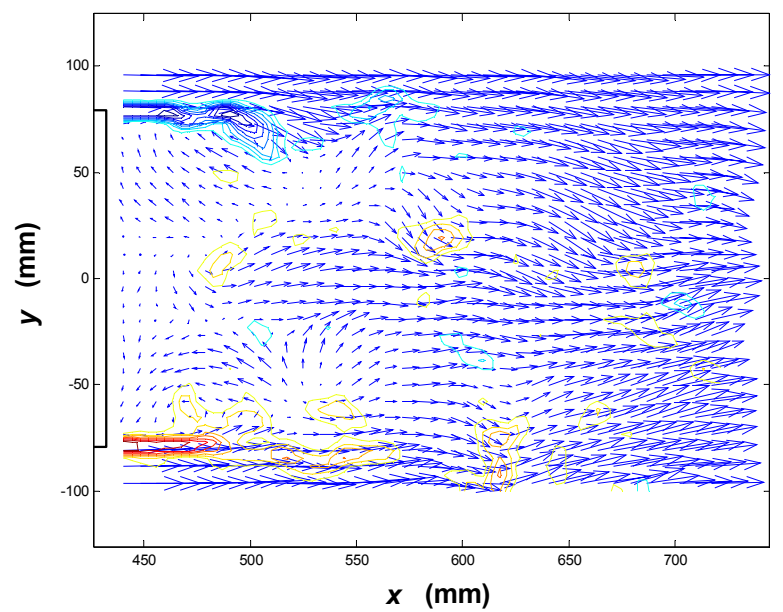

Figure 10. Instantaneous velocity and vorticity fields in the horizontal plane $z=15 \mathrm{~mm}$ behind the tailgate of a pickup truck at a free stream velocity $30 \mathrm{~m} / \mathrm{s}$ $\left(\operatorname{Re}=2.88 \times 10^{5}\right)$.

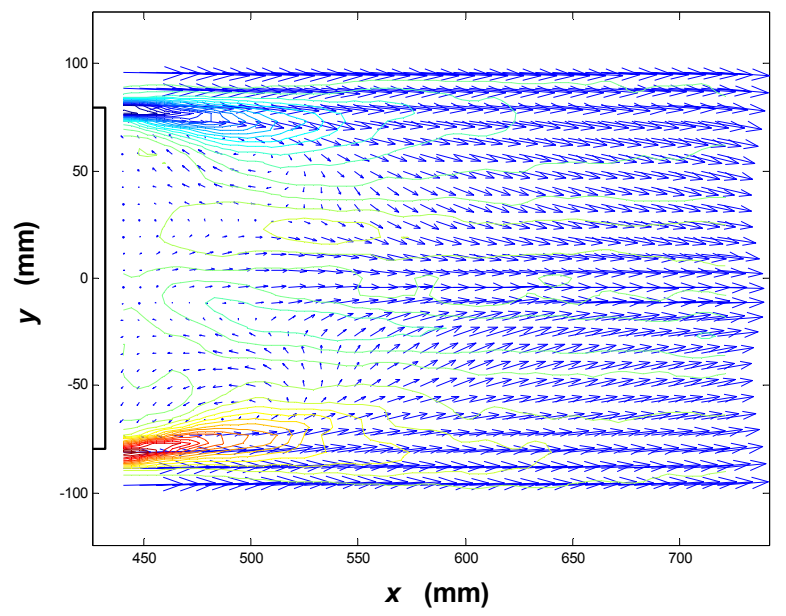

Figure 11. Mean velocity field and vorticity fields in the horizontal plane at $\mathrm{z}=15 \mathrm{~mm}$ behind the tailgate of a pickup truck. $\left(\operatorname{Re}=2.88 \times 10^{5}\right)$.

Figure 11 shows the measured mean velocity and mean vorticity field in the horizontal plane at $z=15 \mathrm{~mm}$. Figure 12 shows the streamline pattern computed from the mean velocity field. The regions of high vorticity show the location of the tailgate edge shear layers, which extend to approximately $x=550 \mathrm{~mm}$, the same location as measured for the cab and underbody shear layers. Perhaps the more striking feature of the flow is the relatively high downstream velocity at the symmetry plane. The streamlines plotted in Figure 12 show that the recirculating flow regions develop on both sides of the symmetry plane, while the flow in the symmetry plane is in the downstream direction. The downstream extent of these recirculating flow regions is approximately $100 \mathrm{~mm}$. As noted earlier these features of the flow are attributed to three-dimensional effects associated with the development of streamwise vorticity.

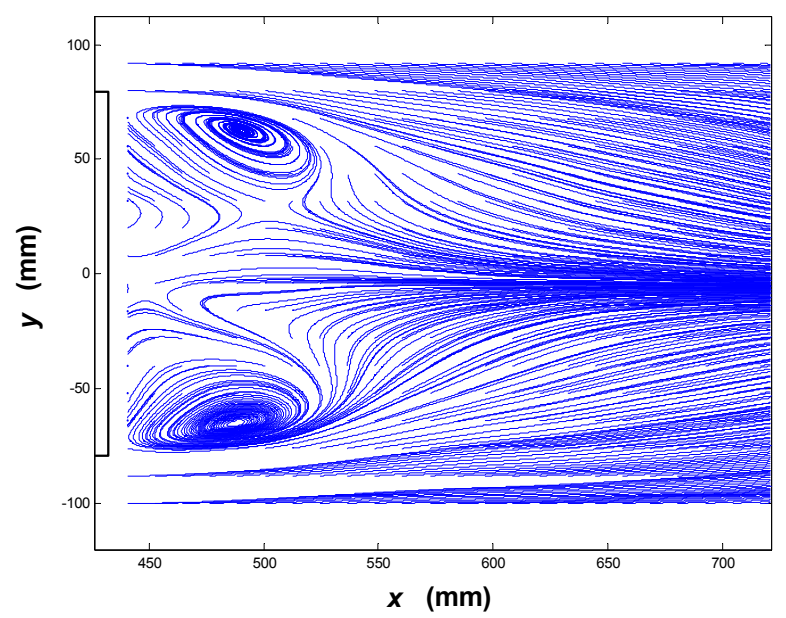

Figure 12. Streamlines of the mean velocity field in the horizontal plane at $z=15 \mathrm{~mm}$. $\left(\operatorname{Re}=2.88 \times 10^{5}\right)$.

\section{Bed Flow}

Figure 13 shows the mean velocity profiles in the symmetry plane of the flow over the bed for the three Reynolds number considered in this investigation. The plots shows the results of two separate tests one for the flow outside the bed and the other for the flow inside the bed. The data at different Reynolds numbers collapse on a single curve indicating that Reynolds number effects are very small at the present flow conditions. Figure 10(a) shows the streamwise velocity profiles at several downstream locations. Note that the cab base is located at $\mathrm{x}=280 \mathrm{~mm}$. Inside the bed the $u$ velocities are negative indicating an upstream flow. It is clear from the $u / U$ and $w / U$ profiles that the flow enters the bed near the tailgate and leaves it near the cab base. The maximum reversed velocity inside the bed is approximately 0.32 times the freestream speed.

Figure 14 shows profiles of the second order turbulent velocity correlations in the symmetry plane. The normal correlation, $\overline{\mathrm{u}^{\prime 2}} / \mathrm{U}^{2}$ shown in Figure 14(a), in the cab shear layer is about 0.01 , and remains almost constant over the entire bed. Inside the bed the normal correlation, $\overline{\mathrm{u}^{\prime 2}} / \mathrm{U}^{2}$, increases towards the tailgate, although the maximum value is approximately half the value in the shear layer. The maximum normal correlation in the traverse direction, $\overline{\mathrm{w}^{\prime 2}} / \mathrm{U}^{2}$ shown in Figure $14(b)$, is about half that of $\overline{u^{\prime 2}} / U^{2}$. However, it is larger inside the bed than in the shear layer. Similarly the magnitude of the shear correlation, $\overline{u^{\prime} w^{\prime}} / U^{2}$ shown in Figure $14(\mathrm{c})$, is smaller in the cab shear layer compared to inside the bed. Maxima are found near the 
tailgate presumably associated with the interaction of the cab shear layer and the tailgate.

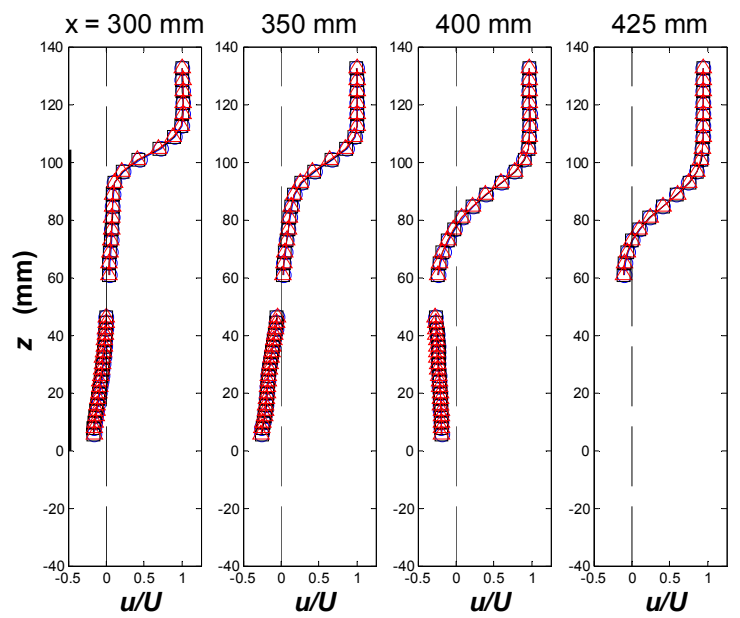

(a)

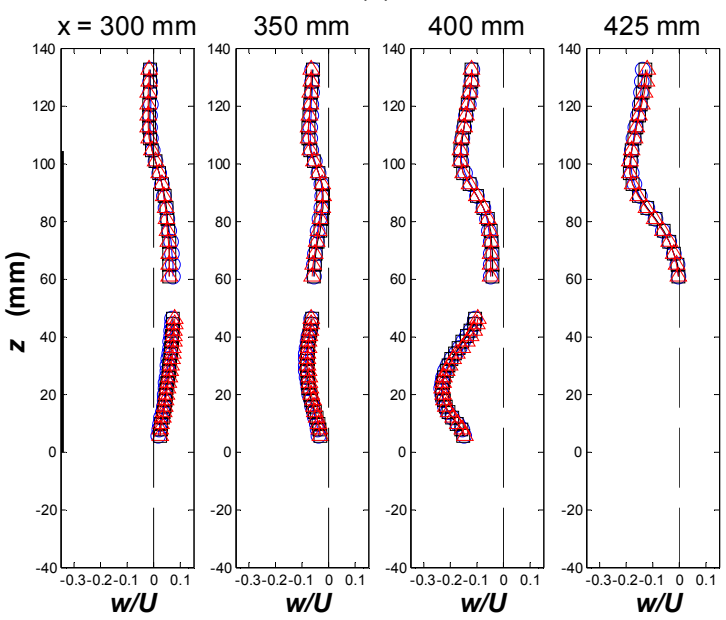

(b)

Figure 13. Mean velocity profiles of the flow in the symmetry plane of the wake over the bed: (a) streamwise velocity, (b) vertical velocity. $\vartheta, \operatorname{Re}=174,000 ; \square, \operatorname{Re}=236,000$; and $\triangle, \operatorname{Re}=288,000$.

\section{Tailgate Flow}

The mean velocity profiles for the flow behind the tailgate at the symmetry plane are shown in Figure 15. The downstream evolution of $u / U$ shown in Figure 15(a) indicates a reduction of the maximum velocity in the underbody flow as the shear layer width increases. Moreover, the maximum upstream velocity in the wake of the tailgate is very small (i.e. $u / U=-0.05$ ) compared to the flow behind the cab (i.e. $u / U=-0.3$ ). The $w / U$ velocity profiles are shown in Figure 15(b). These results show a downward flow in the symmetry plane. The downstream location of the negative maxima, $w / U=0.35$, is approximately at $\mathrm{x} \sim 500 \mathrm{~mm}$, which corresponds to 68 $\mathrm{mm}$ from the tailgate.

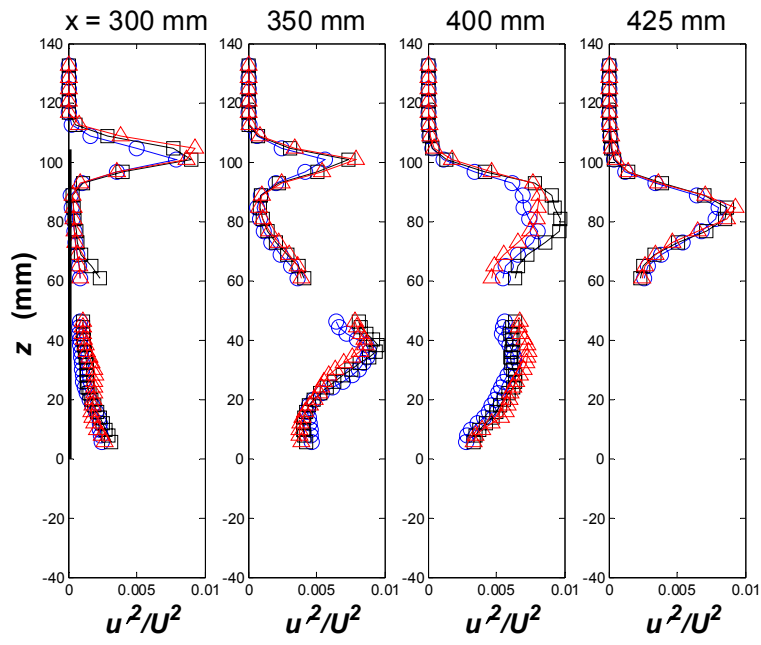

(a)

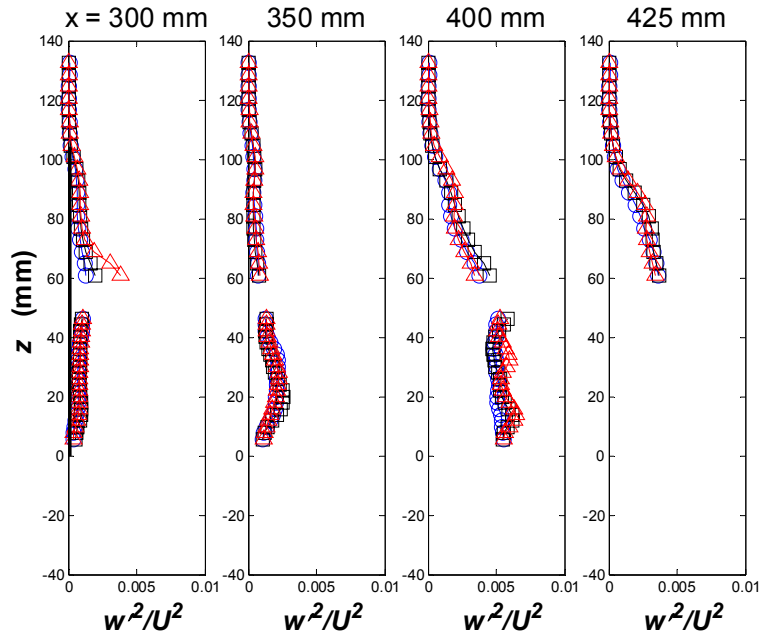

(b)

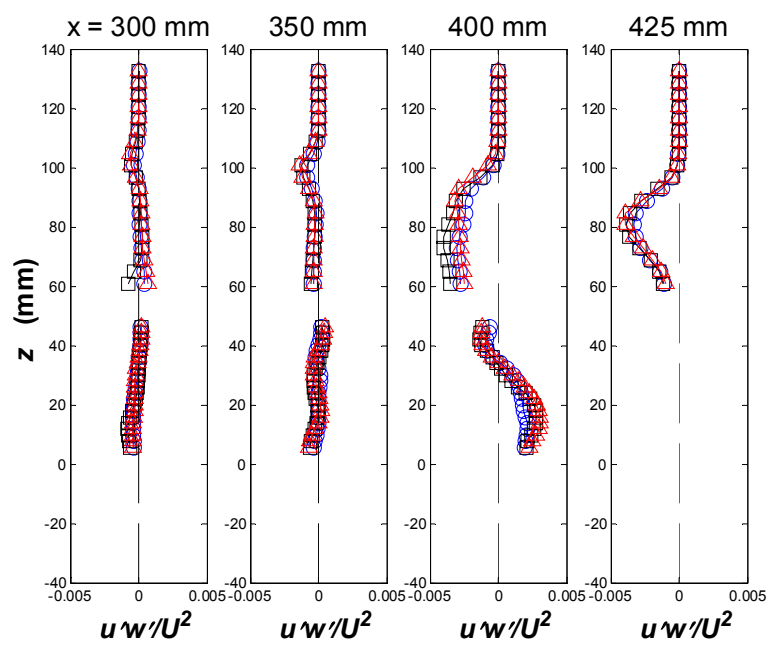

(c)

Figure 14. Profiles of turbulence properties in the symmetry plane of the wake over the bed: (a) $\overline{u^{\prime 2}} / U^{2}$, (b) $\overline{w^{\prime 2}} / U^{2}$, and (c) $\overline{u^{\prime} w^{\prime}} / U^{2}$. $\ominus, \operatorname{Re}=174,000 ; \square, R e=236,000$; and $\triangle, \operatorname{Re}=288,000$. 


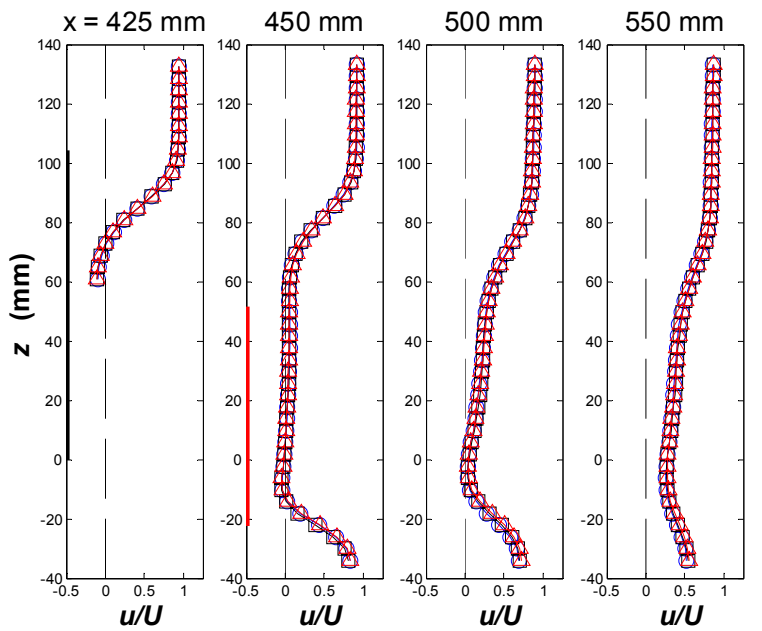

(a)

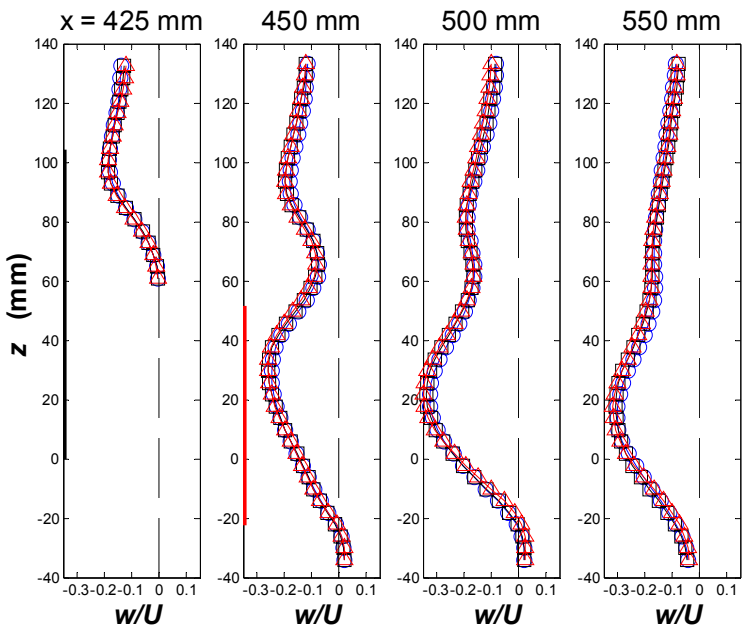

(b)

Figure 15 . Mean velocity profiles in the symmetry plane of the wake behind the tailgate: (a) streamwise velocity, (b) vertical velocity. The location of the cab base is shown in the plots for $x=425 \mathrm{~mm}$. The location of the tailgate is shown in the plots for $x=450 \mathrm{~mm}$. $\vartheta, \operatorname{Re}=174,000 ; \square, \operatorname{Re}=236,000$; and $\triangle$, $\operatorname{Re}=288,000$.

The second order velocity correlations in the symmetry plane behind the tailgate are shown in Figure 16. Note that the magnitudes of the second order correlations are larger by a factor of two compared to bed flow values. These data show two distinct regions: the underbody shear layer and the tailgate edge flow. Profiles of the normal velocity correlation $\overline{\mathrm{u}^{\prime 2}} / \mathrm{U}^{2}$ are shown in Figure 16(a). Maximum values are found in the underbody flow shear layer. The downstream evolution shows an increase in magnitude up to $x=500 \mathrm{~mm}$, followed by a reduction in magnitude farther downstream. The cab shear layer can be found at $z \sim 80 \mathrm{~mm}$, and a high turbulence intensity region is observed at the edge of the tailgate, $\quad z \sim 40 \mathrm{~mm}$. These two regions merge downstream of $x \sim 500 \mathrm{~mm}$. In contrast to the underbody flow shear layer and the cab shear layer, the magnitude of the velocity correlation in this region shows significant Reynolds number effects.

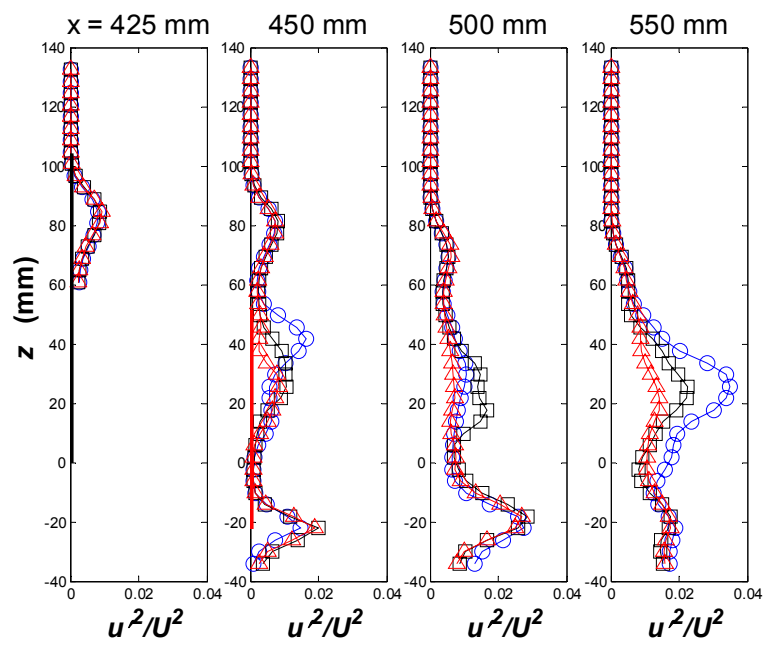

(a)

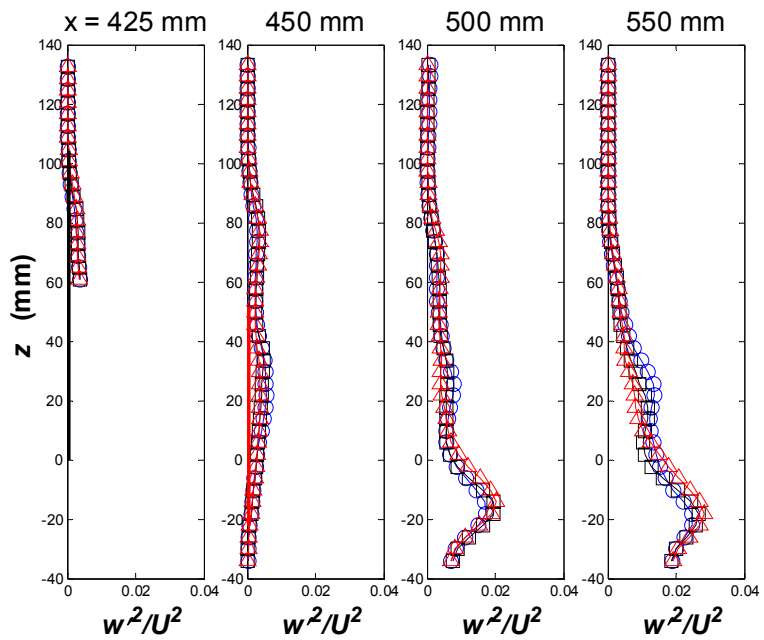

(b)

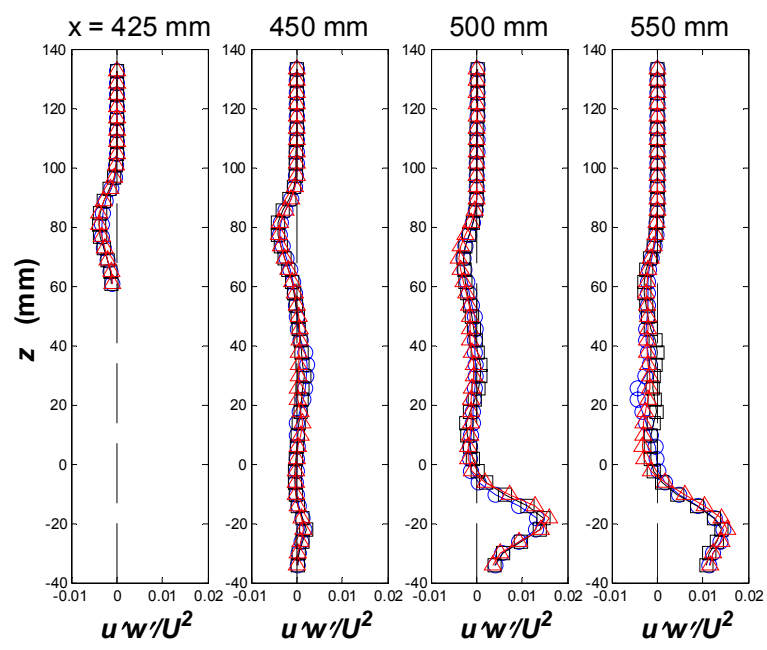

(c)

Figure 16. Profiles of turbulence properties in the symmetry plane of the wake behind the tailgate: (a) $\overline{u^{\prime 2}} / U^{2}$, (b) $\overline{w^{\prime 2}} / U^{2}$ and (c) $\overline{u^{\prime} w^{\prime}} / U^{2} . \quad \ominus, \operatorname{Re}=174,000$; $\square, \operatorname{Re}=236,000$; and $\triangle, \operatorname{Re}=288,000$. 
The profiles of the $\overline{w^{\prime 2}} / U^{2}$ velocity correlation are shown in Figure 16(b). These data show similar structure as the $\overline{\mathrm{u}^{\prime 2}} / \mathrm{U}^{2}$ velocity correlations. The location of the maximum value of the $\overline{\mathrm{w}^{\prime 2}} / \mathrm{U}^{2}$ correlation $(=0.025)$ is in the underbody flow shear layer at $\mathrm{x}=550 \mathrm{~mm}, \mathrm{z} \sim-20 \mathrm{~mm}$. Similarly profiles of the shear correlation $\overline{u^{\prime} w^{\prime}} / U^{2}$ in Figure $16(\mathrm{c})$ show the same structure as the $\overline{u^{\prime 2}} / U^{2}$. The maximum shear correlation in the underbody shear layer is about 0.018 compared to 0.005 in the cab shear layer.

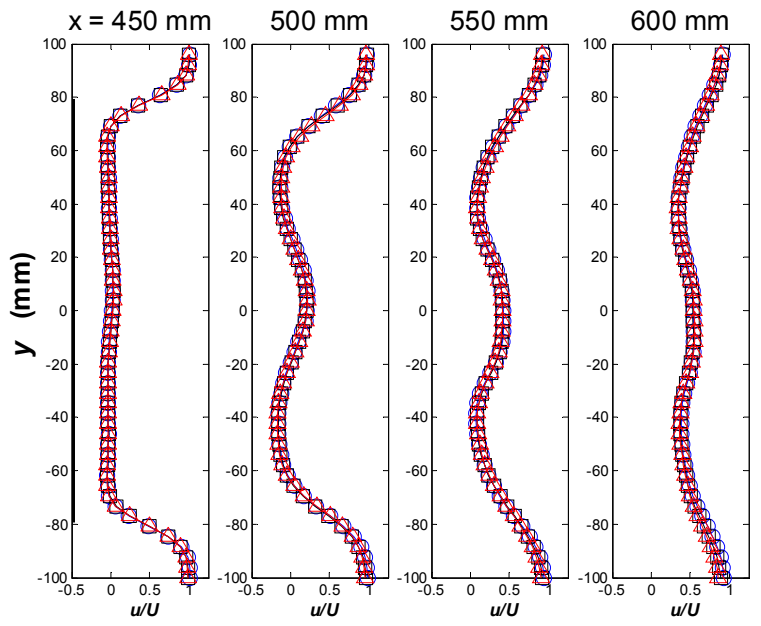

(a)

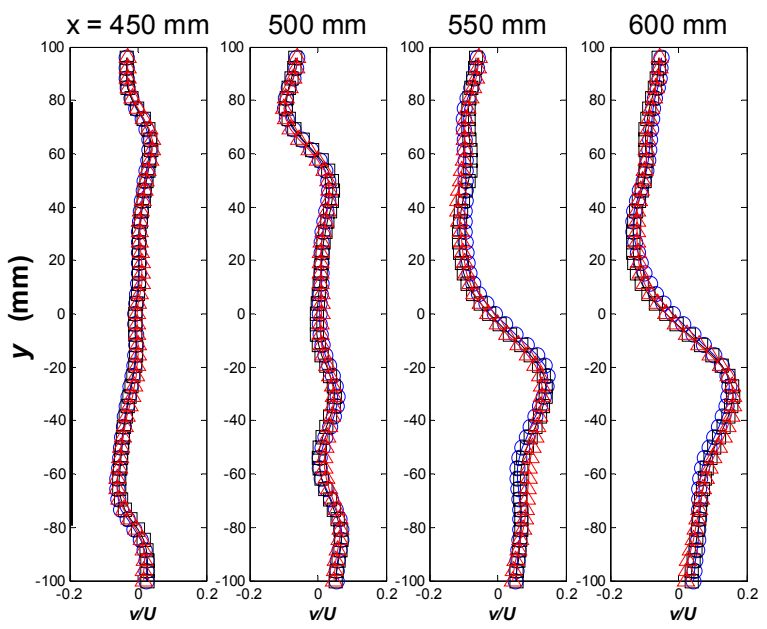

(b)

Figure 17. Mean velocity profiles of the flow in the $z=15 \mathrm{~mm}$ plane of the wake behind the tailgate: (a) streamwise velocity component, (b) lateral velocity component. $\theta$, Re $=174,000 ; \square, \operatorname{Re}=236,000$; and $\triangle, \operatorname{Re}=288,000$.

Mean velocity profiles in horizontal plane $z=15 \mathrm{~mm}$ behind the tailgate are shown in Figure 17. The downstream evolution of $u / U$ in Figure 17(a) shows the evolution of shear layers at the side edges of the tailgate and a region of high velocity at the symmetry plane. The velocity in the symmetry plane increases very rapidly with downstream distance reaching a value of 0.74 at $x=700 \mathrm{~mm}$ (not shown in the plot). Reversed flow regions are found at $x=500 \mathrm{~mm}$ on both sides of the symmetry plane. Profiles of the normalized mean lateral velocity, $v / U$, are shown in Figure 17(b). The magnitude increases with downstream distance reaching a maximum value of approximately \pm 0.15 at $x=600 \mathrm{~mm}$ and decreasing farther downstream.

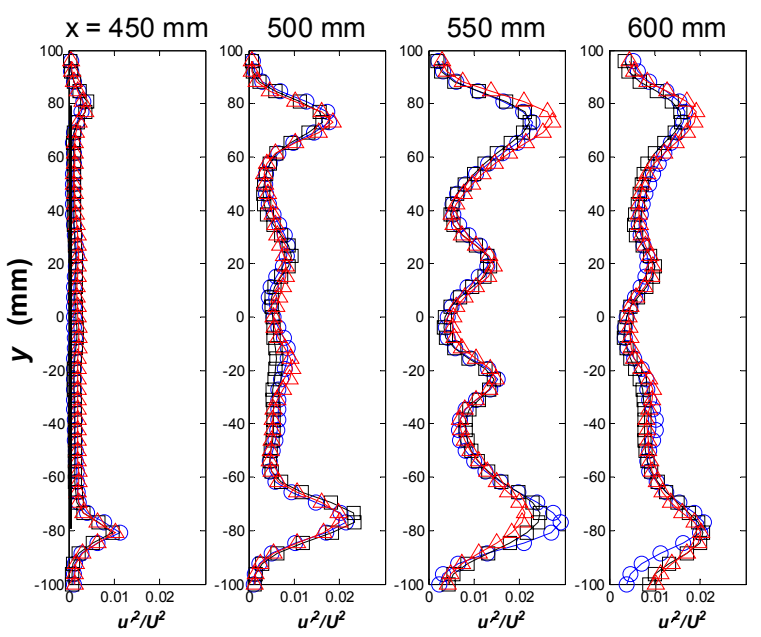

(a)

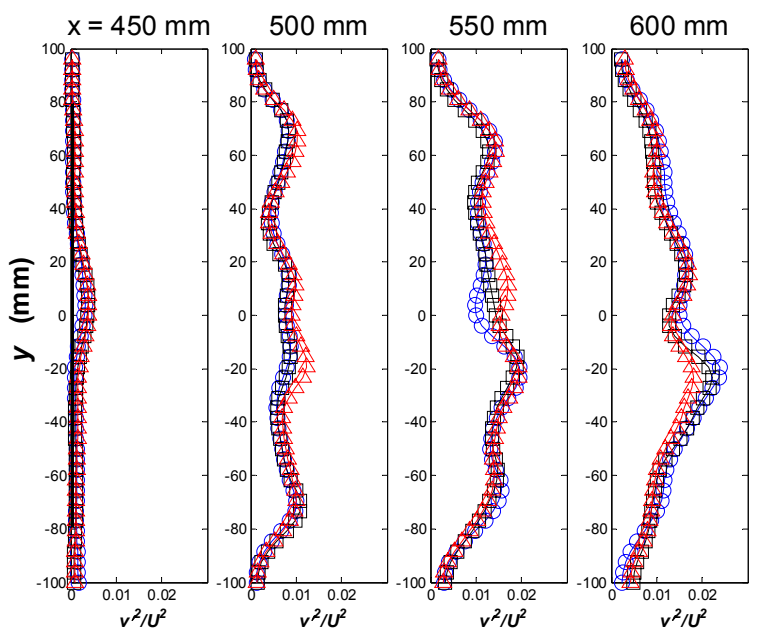

(b)

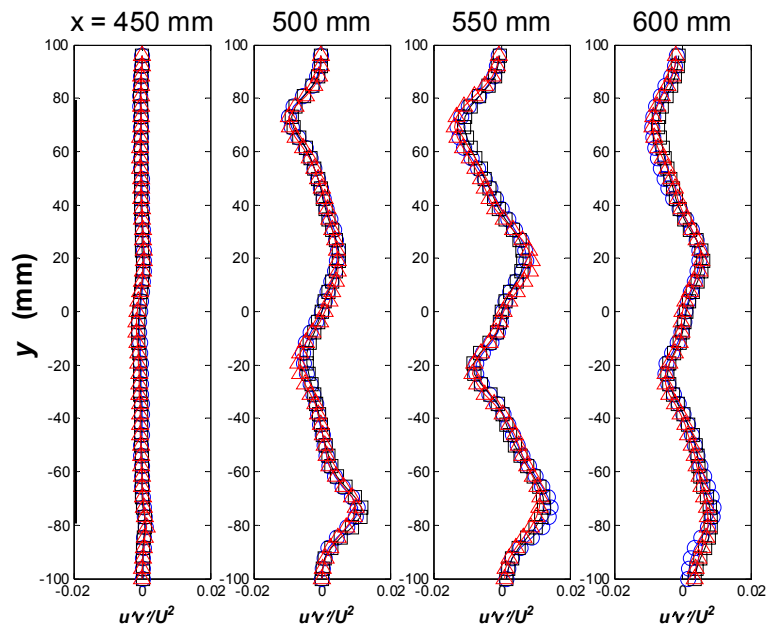

(c)

Figure 18. Profiles of turbulence properties in the $z=15 \mathrm{~mm}$ plane of the wake behind the tailgate: (a) $\overline{\mathrm{u}^{\prime 2}} / \mathrm{U}^{2}$, (b) $\overline{v^{\prime 2}} / U^{2}$ and (c) $\overline{u^{\prime} v^{1}} / U^{2} . \quad \ominus, \operatorname{Re}=174,000$; $\square, \operatorname{Re}=236,000$; and $\triangle, \operatorname{Re}=288,000$. 
The second order velocity correlations in the horizontal plane $z=15 \mathrm{~mm}$ are shown in Figure 18. In this plane the magnitude is comparable to the values in the symmetry plane. The results for the normal velocity correlation $\overline{\mathrm{u}^{\prime 2}} / \mathrm{U}^{2}$ in Figure 18(a) show two maxima at $\mathrm{y}= \pm 80 \mathrm{~mm}$ corresponding to the location of the edge shear layers. The magnitude at the maxima increase with downstream distance up to $x=550 \mathrm{~mm}$ and then decrease further downstream. The maximum value at this location is $\overline{\mathrm{u}^{\prime 2}} / \mathrm{U}^{2}=0.027$. Two other maxima develop at $y= \pm 20 \mathrm{~mm}$. These local maxima also increase with downstream distance reaching the absolute maxima at $x=550 \mathrm{~mm}$, and the corresponding values is $\overline{u^{\prime 2}} / U^{2}=0.014$. The results for the normal velocity correlation $\overline{v^{\prime 2}} / U^{2}$ in Figure 18(b) show relatively smaller amplitude at the edge shear layers and generally larger values at the symmetry plane. Figure 18(c) shows the $\overline{u^{\prime} v^{\prime}} / U^{2}$ profiles. The maximum correlation is found in the edge shear layers and a local maxima are found at $y= \pm 20 \mathrm{~mm}$. These results show that the downwash in symmetry plane produces internal shear layers with turbulence properties comparable in magnitude to the shear layers at the tailgate edge.

\section{CONCLUSION}

An investigation of the flow in the near wake of a pickup truck model has been conducted. The main conclusions of the investigation are:

- Mean pressure data show the expected behavior at the front of cab, and a cab base pressure coefficient in the range $C_{p} \sim-0.25$ to -0.35 .

- The mean pressure distribution on the tailgate show a lower pressure coefficient on the inside surface compared to the outside surface suggesting that the tailgate reduces aerodynamic drag.

- The rms value of pressure fluctuations at the cab base is very low and increases significantly towards the back of the bed and the tailgate top edge.

- Spectra of the pressure fluctuations at the tailgate edge show a spectral peak at a Strouhal number of 0.07 based on width. This result is consistent with base pressure fluctuations spectra measured in simplified model geometries.

- These power spectra measurements also show large spectral density at very low frequency. This is a poorly understood feature of the flow associated with sensitivity of the flow to disturbances in the free stream.

- Mean velocity field measurements in the symmetry plane show a recirculating flow region over the bed bounded by the cab shear layer. The rms value of the turbulence intensity in the shear layer is approximately $10 \%$ of the free stream velocity.
- The cab shear layer does not interact directly with the tailgate. The location of the maximum turbulence intensity in the cab shear layer is found above the tailgate edge at $z \sim 80 \mathrm{~mm}$.

- The underbody flow results in the formation of a strong shear layer in the near wake. This shear layer has the highest turbulence intensity in the near wake of the pickup truck flow.

- Shear layers also form at the side edges of the tailgate, and on the top edge of the tailgate with turbulence intensity comparable to the underbody flow shear layer.

- One of the more striking features of the pickup truck flow is the downwash on the symmetry plane behind the tailgate, and the formation of two smaller recirculating flow regions on both sides of the symmetry plane. These features are consistent with the formation of streamwise vortices in the wake.

- Regions of high turbulence intensity separate the downwash region from the recirculating flow regions and the tailgate edge shear layers.

\section{REFERENCES}

1. Hucho, W.H., Aerodynamics of Road Vehicles, SAE International, Warrendale, Pa, 1998.

2. Balkanyi, S.R., Bernal, L.P., Khalighi, B., and Sumantran, V.," Dynamics of Manipulated Bluff Body Wakes," AIAA Paper 2000-2556, 2000.

3. Khalighi, B. Zang, S., Koromilas, C., Balkanyi, S., Bernal, L.P., laccarino, G. and Moin, P., "Experimental and computational study of unsteady wake flow behind a body with a drag reduction device," SAE Paper 2001-01-1042.

4. Balkanyi, S., Bernal, L.P. and Khalighi, B., "Analysis of the near wake of bluff bodies in ground proximity," ASME Paper 2002-32347.

5. Lanser, W.R., Ross, J.C. and Kaufman, A.E., "Aerodynamic performance of a drag reduction device on a full-scale tractor/trailer," SAE Paper 912125, 1991.

6. Duell, E.G. and George, A.R., "Experimental study of a ground vehicle body unsteady near wake," SAE Paper 1999-01-0812.

7. Lietz, R., Pien, W., Hands, D., and McGrew, J., "Light truck aerodynamic simulations using a lattice gas based simulation technique," SAE Paper 199901-3756, 1999.

8. Sims-Williams, D.B., Dominy, R.G., and Howell, J.P., "An Investigations into large scale unsteady structures in the wake of real and idealized hatchback car model," SAE Paper 2001-01-1041, 2001. 